\title{
Inguinal hernias in children
}

Evie Yeap, Ramesh M Nataraja, Maurizio Pacilli

\section{Background}

An inguinal hernia is one of the most common paediatric surgical presentations in a primary care setting. Hernias can present in multiple ways, ranging from an emergency such as a strangulated hernia to a less urgent reducible hernia.

\section{Objective}

The aim of this article is to aid in appropriate diagnosis and management of hernias in children. The article also provides useful tips for hernia reduction that are especially beneficial in the primary care setting and assist with the identification of hernias that require urgent referral.

\section{Discussion}

Recognising the signs of a hernia containing compromised contents is essential to prevent serious complications such as intestinal perforation, testicular atrophy and ovarian damage. Other common conditions such as hydrocoele and undescended testis are sometimes confused with an inguinal hernia. Young patients under the age of three months and patients with concern for compromised contents require urgent referral. Recent evidence regarding controversial issues in inguinal hernia repair such as the role of laparoscopy and the relevance of a contralateral patent internal inguinal ring will be discussed.
INGUINAL HERNIA is a common paediatric surgical problem. ${ }^{1}$ The incidence in full-term babies is estimated at $1-5 \%$, and it is six times more common in boys. ${ }^{2-4}$ The small intestines are the most commonly herniated intra-abdominal content in boys. ${ }^{5}$ In female infants, the ovaries are the most commonly herniated content; however, after one year of age, bowel becomes more common, and a herniated ovary in an adolescent would be extremely unlikely. ${ }^{5}$ The incidence of right-sided hernias is more than three times that of left-sided hernias. ${ }^{2-3}$ Bilateral hernias are more common in premature infants. ${ }^{3,5}$ In a female full-term infant, bilateral inguinal hernias that may contain ovaries should prompt investigation for a possible androgen insensitivity syndrome.

Over $99 \%$ of inguinal hernias in children are indirect. ${ }^{1}$ During development, an outpouching of the peritoneum (processus vaginalis) forms with the testicular descent into the scrotum in buys or in the formation of the labia in girls. If this subsequently fails to obliterate, it is a patent processus vaginalis (PPV). This lies within the inguinal canal, together with the spermatic cord in boys and the round ligament in girls. An indirect hernia occurs when intra-abdominal content herniates through the internal (deep) inguinal ring into the inguinal canal following the path of testicular descent. These contents then exit through the external (superficial) inguinal ring and enter the scrotum. As an indirect hernia enters the canal through the deep ring, it arises lateral to the inferior epigastric vessels. If the PPV is narrow, a hydrocoele may develop. Asymptomatic PPV occurs in up to $20 \%$ of infants and may persist in up to $19 \%$ of adults. ${ }^{3}$
A direct hernia is extremely rare in children and involves herniation of intra-abdominal content through a weakness in the posterior wall of the canal, known as Hesselbach's triangle. The lateral border of the triangle is formed by the inferior epigastric vessels, the medial border is the lateral edge of the rectus sheath and the base is the inguinal ligament. A direct hernia is found medial to the inferior epigastric vessels, while an indirect hernia is found lateral to these vessels.

\section{Pathophysiology}

The reason for the processus vaginalis' failure to close in some individuals is largely unknown. ${ }^{6}$ Some evidence suggests that smooth muscle cells involved in the descent of the testis may abnormally fail to undergo apoptosis in inguinal hernias. ${ }^{3}$

\section{Presentation}

Patients usually present once a parent or carer has noticed a lump or swelling in the groin. Carers may report a change in size with coughing or crying, although it can be difficult to determine if the lump causes pain (and hence the crying) or if the lump is more noticeable with crying. Careful history and examination can usually differentiate other causes of groin lumps such as undescended testes and hydrocoele (refer to Table 1 and 'Diagnosis' section). The examiner will not be able to 'get above' (feel the uppermost border of) the swelling if it is a hernia, and a hernia will not transilluminate except occasionally in a neonate with a very thin bowel wall.

Hernias can be classified as reducible or irreducible. If the hernia is irreducible, 
an important distinction to make is between strangulated and non-strangulated hernias. A strangulated hernia develops when the blood supply to the intestines is compromised. This is a surgical emergency as it causes intestinal obstruction, ischaemia, subsequent necrosis and perforation and is therefore associated with erythema, oedema and pain. In boys, irreducible hernias can cause testicular damage; testicular atrophy has been found in $15 \%$ of irreducible hernias and is thought to be secondary to a local pressure effect. ${ }^{1}$ Similarly, ovarian damage may occur in girls. ${ }^{1}$

\section{Diagnosis}

Some important questions for parents or carers who present with a child with a possible inguinal hernia include when it was first seen, what its exact position is and whether it has changed in size.

To diagnose a hernia:

- Ensure the child is warm and comfortable during the examination.

- Note the size and extent of any swelling and whether there are any skin changes.

- Check whether you can get above the swelling, whether the swelling moves with traction on the testis and whether there is transillumination (Table 1).

- In male patients, roll the spermatic cord against the pubic tubercle; it is said to feel thicker and like two pieces of silk rubbing over each other if there is an inguinal hernia due to the peritoneal layers of the PPV (the so-called 'silk glove sign'). ${ }^{2}$

- In female patients, an ovary may palpate similarly to a lymph node. The presence of an ovary in the inguinal canal does not in itself warrant urgent repair, and there is some evidence that an ovary within an inguinal hernia may spontaneously reduce, allowing elective repair to occur when the child is older. ${ }^{7}$ If the ovary is tender, this is a surgical emergency as torsion may be present.

\section{Incarcerated hernia}

To establish whether there is a possibility of intestinal obstruction, it is necessary to ascertain whether the abdomen is more distended than usual or if there are any associated symptoms such as vomiting, irritability and pain. These symptoms, in addition to oedema, erythema and tenderness, may indicate incarceration. ${ }^{4}$ In girls, any tenderness or swelling may indicate ovarian torsion and therefore requires urgent referral.

\section{Differential diagnosis}

Other important diagnoses are listed in Table 1. Hydrocoeles often present for the first time with a concurrent viral illness, as this increases the amount of intraperitoneal fluid, while coughing increases intra-abdominal pressure. Hydrocoeles are usually irreducible but after a period of inactivity, such as overnight, may reduce. Similarly, inguinal lymphadenopathy may be confused with an inguinal hernia. Idiopathic scrotal oedema may be recognised by a subacute redness and swelling that is not usually painful. An abscess in the inguinal region may also be confused with an incarcerated hernia; however, a short history of a new lump and other features indicative of infection such as the presence of purulent fluid would be characteristic.

Less common differentials in this age range would include varicoceles (recognised by a 'bag of worms' sensation

\section{Table 1. Differential diagnosis and diagnostic features}

\begin{tabular}{|c|c|c|c|c|}
\hline Examination features & Inguinal hernia & Hydrocoele & $\begin{array}{l}\text { Encysted hydrocoele } \\
\text { of the cord }\end{array}$ & Undescended testis \\
\hline Is the hernia reducible? & Yes, if not incarcerated & $\begin{array}{l}\text { No, the opening to the } \\
\text { abdominal peritoneal } \\
\text { cavity is often too small to } \\
\text { allow reduction of the fluid }\end{array}$ & No & No \\
\hline Skin changes & $\begin{array}{l}\text { May be oedematous } \\
\text { or erythematous if } \\
\text { incarcerated }\end{array}$ & No & No & No \\
\hline Tenderness & Yes, if incarcerated & No & No & No \\
\hline $\begin{array}{l}\text { Can you get above the } \\
\text { swelling? }\end{array}$ & No & Yes & $\begin{array}{l}\text { Yes, the cyst will also } \\
\text { move readily with } \\
\text { traction on the cord }\end{array}$ & Yes \\
\hline Transillumination & $\begin{array}{l}\text { No, except in neonates } \\
\text { when the intestines wall } \\
\text { may be very thin }\end{array}$ & $\begin{array}{l}\text { Yes, the testis may be } \\
\text { seen as a dark shadow }\end{array}$ & $\begin{array}{l}\text { May transilluminate, but } \\
\text { not always }\end{array}$ & No \\
\hline Management & $\begin{array}{l}\text { Requires referral to } \\
\text { paediatric surgeon }\end{array}$ & $\begin{array}{l}\text { Can be observed and } \\
\text { usually resolves within } \\
\text { the first two years of life. } \\
\text { If persists beyond this } \\
\text { age, requires referral to } \\
\text { paediatric surgeon }\end{array}$ & $\begin{array}{l}\text { Similar management to } \\
\text { hydrocoeles }\end{array}$ & $\begin{array}{l}\text { Requires referral to } \\
\text { paediatric surgeon if } \\
\text { persists after three } \\
\text { months of age }\end{array}$ \\
\hline
\end{tabular}


on examination) and testicular tumours. In the case of a testicular tumour, the examiner would easily be able to get above a testicular mass and it would not be reducible. In a more acute setting, it would be important to consider if testicular torsion could be a possibility. This could be recognised by a lack of cremasteric reflex, erythematous and swollen testis and abnormal lie.

\section{Tips for attempting reduction}

If the child is unwell or reduction is not possible, they require urgent referral to the emergency department and paediatric surgeon

When attempting reduction:

1. Obtain parental consent.

2. Ensure that the environment is suitable and warm.

3. Use the thumb and index finger of one hand to push downwards to create a funnel at the superficial inguinal ring.

4. Gently apply pressure superiorly and laterally with the thumb, index and middle finger of the other hand and direct the hernia towards the internal ring.

5. Using a circular motion, apply gradual pressure and guide the hernia into the ring; displacing the scrotum medially may also assist in reduction (Figure 1).

6. If unsuccessful, refer urgently to the paediatric emergency department.

\section{Investigations}

An inguinal hernia is a clinical diagnosis and no investigations are necessary prior to referral of children with a reducible hernia. In particular, ultrasonography is often not required to facilitate diagnosis and may delay management.

\section{Management}

The referral guidelines for inguinal hernia vary in urgency based on the likelihood of becoming irreducible and hence containing compromised intestines (Figure 2).

Urgent referral to a paediatric surgeon is required for children aged $<3$ months with a hernia; these children should usually be seen within a week. A referral to the emergency department is required if the hernia cannot be reduced or if it is tender. Simple analgesia can be used while attempting reduction and in those sent to the emergency department. Infants aged $<1$ year may have an increased risk of strangulation up to two-fold, with the highest risk in the first few months of life..$^{8-9}$

\section{Controversial issues in hernia repair}

There has been much debate over the benefits of laparoscopic versus open inguinal hernia repair, but overall there is little difference in clinical outcomes. ${ }^{10-12}$ Laparoscopic repair has been performed in children of all ages including premature infants. The advantages of the laparoscopic approach may include a lower risk of cord damage causing testicular atrophy and a lower rate of postoperative complications such as wound infection, hydrocoele and scrotal oedema. ${ }^{10-13}$

Figure 3 shows potential findings during laparoscopic repair of an inguinal hernia. The oedema noted in Figure 3B is typical after incarceration; note that this image depicts a right indirect inguinal hernia as the inferior epigastric vessels are medial to it (to the left of the image in this view).
Laparoscopy facilitates easy detection of a patent contralateral internal inguinal ring, potentially preventing the need for a second operation or incision. ${ }^{13}$ This might be an important consideration for patients who live some distance from a paediatric centre - which could cause significant delay to treatment - or who have a high anaesthetic risk. However, only 5-7\% of patients with a contralateral PPV develop a contralateral hernia later in life, known as a metachronous contralateral inguinal hernia (MCIH). ${ }^{13-14}$ Eighteen PPVs need to be closed to prevent one MCIH. ${ }^{14} \mathrm{An}$ open inguinal ring is detected in $30 \%$ of children, so the natural history of this open ring is not clear; however, an indirect inguinal hernia is still a common disease in adults. ${ }^{13}$ Younger patients ( $<6$ months) and those who initially presented with a left-sided hernia are more likely to develop a MCIH; the number needed to treat in either of these groups decreases to nine. ${ }^{14}$

Some paediatric surgeons traditionally advocated for routinely exploring the contralateral inguinal region for an asymptomatic open inguinal ring while performing a repair in girls because the most concerning risk of injury to the vas

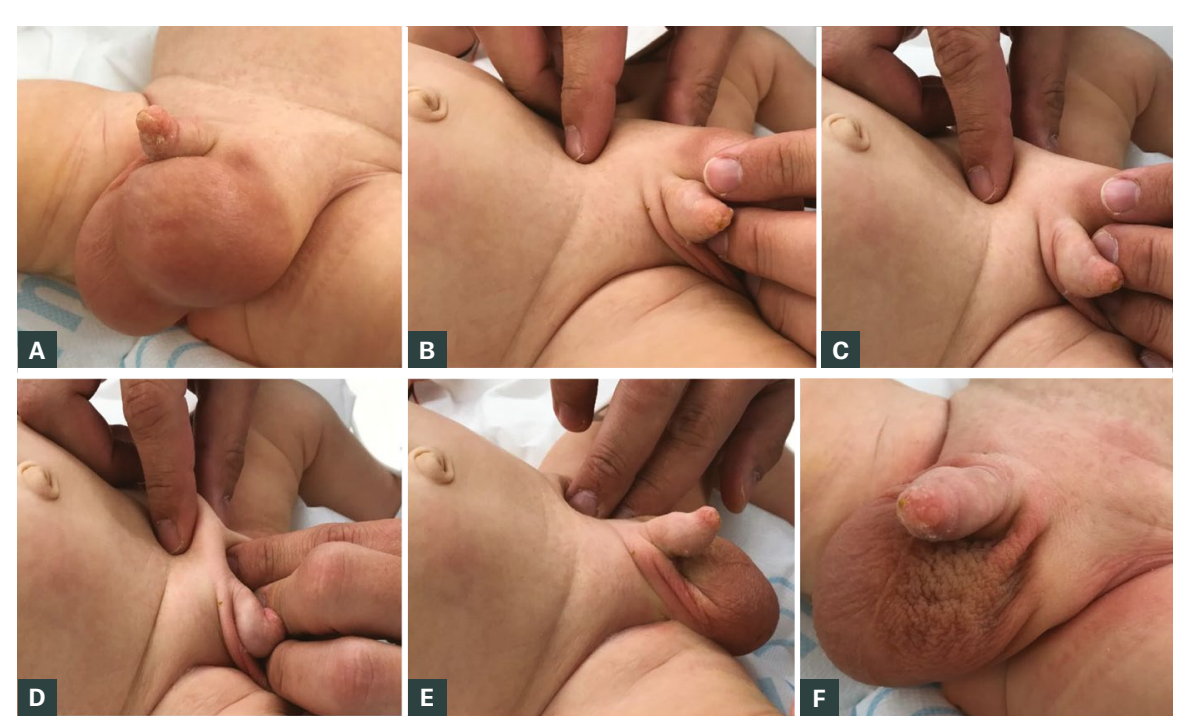

Figure 1. Clinical reduction of an inguinal hernia

A. Large left-sided inguinoscrotal hernia; B. Intestines positioned in line with the inguinal canal and displacement of scrotum medially; $\mathbf{C}$. Funnel created at the level of the superficial inguinal ring; D. Hernia reduced with circular motion; E. With the hernia reduced you can now get above it; F. Appearance of reduced inguinal hernia 


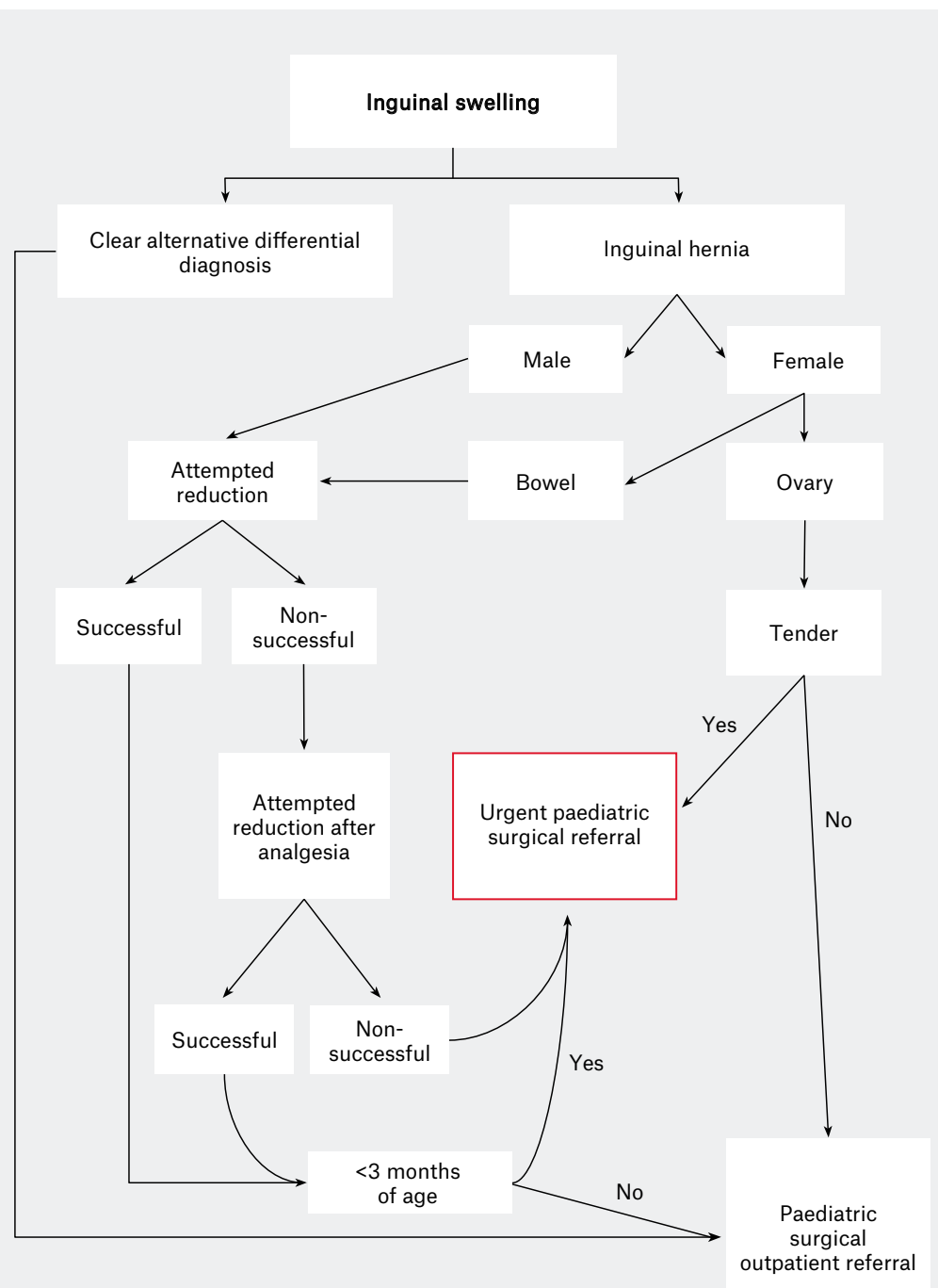

Figure 2. Flow diagram for the clinical management of a paediatric inguinal hernia deferens or testicular vessels is not an issue. Although laparoscopic repair of the contralateral side is associated with fewer complications when compared with open surgery, parents still need to be appropriately counselled. Moreover, the size of the hernia or whether it has been recently incarcerated does not affect a laparoscopic repair. ${ }^{11}$ In girls, laparoscopy can allow preservation of the round ligament, which some believe has a role in supporting the internal genital organs. ${ }^{15}$ This is predominantly a potential issue with routine bilateral exploration in girls.

Conversely, open unilateral inguinal surgery may involve less anaesthetic time and may also avoid a general anaesthetic with the application of spinal anaesthesia (however, open surgery takes longer than bilateral laparoscopic surgery). ${ }^{10-13}$ Specialist equipment is required for laparoscopic repair and is therefore not available in all centres. Furthermore, it must be noted that during the laparoscopic approach, the peritoneal cavity is routinely entered, with the possible additional risks of damage to intra-abdominal viscera and a lifetime risk of subsequent adhesive small bowel obstruction.

There has been conflicting evidence in the past regarding whether recurrence rates are different between open and laparoscopic surgery. Some evidence has indicated that a non-absorbable suture must be used in laparoscopic surgery, whereas recurrence rates are low even with late absorbable sutures in open surgery. ${ }^{16-17}$ A recent meta-analysis suggests no


Figure 3. Operative laparoscopic images of the internal ring and inguinal hernias in male infants

A. Laparoscopic view of closed internal ring on the left; B. Post-incarceration oedematous right inguinal hernia; C. Giant left inguinal hernia;

D. Right inguinal hernia in Figure 3B post-closure with non-absorbable purse string suture 
difference in recurrence, complications, time to recovery or length of stay between open and laparoscopic techniques. ${ }^{18}$

There has been minimal prospective research on any advantage in cosmesis with either approach, but most evidence suggests equivalent satisfaction with both techniques. ${ }^{11,18,19}$ Although the incision size is smaller, laparoscopic surgery usually requires at least three incisions, compared with one in open surgery, and the larger scar in open surgery is covered by clothing. The non-umbilical incisions are usually stab incisions with no port, typically $3 \mathrm{~mm}$ in length.

Long-term outcomes are not known for laparoscopic surgery as it has been used for a relatively short period of time when compared with open surgery. In many centres, laparoscopic surgery remains a controversial topic for inguinal hernia repair in children and is not performed by all paediatric surgeons. However, it is becoming routine practice in many European and American centres. ${ }^{19-21}$

\section{Authors}

Evie Yeap MBBS (Hons), DipAnat, Surgical Resident, Department of Paediatric Surgery, Monash Children's Hospital, Vic

Ramesh M Nataraja MBBS, BSc (Hons), GCCS (Hons), FRCSEd (Paed Surg), FFSTEd, FRACS (Paeds), Consultant Paediatric and Neonatal Surgeon, Department of Paediatric Surgery, Monash Children's Hospital, Vic; Senior Lecturer, Department of Paediatrics, School of Clinical Sciences at Monash Health, Medicine, Nursing and Health Sciences, Monash University, Vic. ram.nataraja@monashhealth.org

Maurizio Pacilli MBBS (Hons), MD (Res), FRCS (Paed Surg), Consultant Paediatric and Neonatal Surgeon, Department of Paediatric Surgery, Monash Children's Hospital, Vic; Senior Research Fellow, Department of Paediatrics, School of Clinical Sciences at Monash Health, Medicine, Nursing and Health Sciences, Monash University, Vic

Competing interests: None.
Funding: None.

Provenance and peer review: Not commissioned, externally peer reviewed.

\section{References}

1. Hutson JM, O’Brien M, Beasley SW, Teague WJ, King SK. Jones' clinical paediatric surgery. 7th edn Chichester: John Wiley \& Sons, 2015. p. 332.

2. Bowling K, Hart N, Cox P, Srinivas G. Management of paediatric hernia. BMJ 2017;359:j4484. doi: $10.1136 /$ bmj.j4484.

3. Öberg S, Andresen K, Rosenberg J. Etiology of inguinal hernias: A comprehensive review. Front Surg 2017;4:52. doi: 10.3389/fsurg.2017.00052.

4. Weaver KL, Poola AS, Gould JL, Sharp SW, St Peter SD, Holcomb GW 3rd. The risk of developing a symptomatic inguinal hernia in children with an asymptomatic patent processus vaginalis. J Pediatr Surg 2017;52(1):60-64. doi: 10.1016/j.jpedsurg.2016.10.018.

5. Panabokke G, Clifford ID, Craig SS, Nataraja RM. Reduction of paediatric inguinal hernias. Emerg Med Australas 2016;28(2):224-27. doi: 10.1111/1742-6723.12549.

6. Barnett C, Langer JC, Hinek A, Bradley TJ, Chitayat D. Looking past the lump: Genetic aspects of inguinal hernia in children. J Pediat Surg 2009;44(7):1423-31. doi: 10.1016/j. jpedsurg.2008.12.022. 
7. Hirabayashi $T$, Ueno S, Hirakawa H, Tei E, Mori M. Surgical treatment of inguinal hernia with prolapsed ovary in young girls: Emergency surgery or elective surgery. Tokai J Exp Clin Med 2017:42(2):89-95.

8. Zamakhshary M, To T, Guan J, Langer JC. Risk of incarceration of inguinal hernia among infants and young children awaiting elective surgery. CMAJ 2008;179(10):1001-05. doi: 10.1503/cmaj.070923.

9. Teague WJ, King SK. Paediatric surgery for the busy GP - Getting the referral right. Aust Fam Physician 2015;44(12):890-94.

10. Niyogi A, Tahim AS, Sherwood WJ, et al. A comparative study examining open inguinal herniotomy with and without hernioscopy to laparoscopic inguinal hernia repair in pediatric population. Pediatr Surg Int 2010;26(4):387-92. doi: 10.1007/s00383-010-2549-x.

11. Esposito C, St Peter SD, Escolino M, Juang D, Settimi A, Holcomb GW 3rd. Laparoscopic versus open inguinal hernia repair in pediatric patients: $A$ systematic review. J Laparoendosc Adv Surg Tech A 2014;24(11):811-18. doi: 10.1089/lap.2014.0194.

12. Feng $S$, Zhao $L$, Liao $Z$, Chen $X$. Open versus laparoscopic inguinal herniotomy in children: $A$ systematic review and meta-analysis focusing on postoperative complications. Surg Laparosc Endosc Percutan Tech 2015;25(4):275-80. doi: 10.1097/SLE.0000000000000161.
13. Kokorowski PJ, Wang HHS, Routh JC, Hubert KC, Nelson CP. Evaluation of the contralateral inguinal ring in clinically unilateral inguinal hernia: $A$ systematic review and meta-analysis. Hernia 2014;8(3):311-24. doi: 10.1007/s10029-013-1146-z.

14. Nataraja RM, Mahomed AA. Systematic review for pediatric metachronous contralateral inguinal hernia: A decreasing concern. Pediatr Surg Int 2011;27(9):953-61. doi: 10.1007/s00383-011-2919-z.

15. Mollaeian M, Mollaeian A, Ghavami-Adel M, Abdullahi A, Torabi B. Preserving the continuity of round ligament along with hernia sac in indirect inguinal hernia repair in female children does not increase the recurrence rate of hernia. Experience with 217 cases. Pediatr Surg Int 2012;28(4):363-66. doi: 10.1007/s00383-011-3025-y.

16. Shalaby R, Ibrahem R, Shahin M, et al. Laparoscopic hernia repair versus open herniotomy in children: A controlled randomized study. Minim Invasive Surg 2012;2012:484135. doi: 10.1155/2012/484135.

17. Grimsby GM, Keays MA, Villanueva C, et al. Non-absorbable sutures are associated with lower recurrence rates in laparoscopic percutaneous inguinal hernia ligation. J Pediatr Urol 2015;11(5):275.e1-4. doi: 10.1016/j. jpurol.2015.04.029.

18. Dreuning K, Maat S, Twisk J, van Heurn E, Derikx J. Laparoscopic versus open pediatric inguinal hernia repair: State-of-the-art comparison and future perspectives from a meta-analysis. Surg Endosc 2019;33(10):3177-191. doi: 10.1007/s00464-01906960-2.

19. Esposito C, Escolino M, Turrà F, et al. Current concepts in the management of inguinal hernia and hydrocele in pediatric patients in laparoscopic era. Semin Pediatr Surg 2016;25(4):232-40. doi: 10.1053/j.sempedsurg.2016.05.006.

20. Jessula S, Davies D. Evidence supporting laparoscopic hernia repair in children. Curr Opin Pediatr 2018;30(3):405-10. doi: 10.1097/ MOP.0000000000000612.

21. Antonoff MB, Kreykes NS, Saltzman DA, Acton RD. American Academy of Pediatrics Section on Surgery hernia survey revisited. J Pediatr Surg 2005;40(6):1009-14. doi: 10.1016/j. jpedsurg.2005.03.018.

correspondence ajgp@racgp.org.au 